\title{
Eddy Covariance and Sap Flow Measurement of Energy and Mass Exchanges of Woody Crops in a Mediterranean Environment
}

\author{
A. Motisi \\ Dipartimento DEMETRA \\ Università degli Studi di Palermo \\ Italy \\ S. Consoli and R. Papa \\ Dipartimento GeSA \\ Università degli Studi di Catania \\ Italy \\ C. Cammalleri \\ Dipartimento DICA \\ Università degli Studi di Palermo \\ Italy
}
F. Rossi
Istituto di Biometeorologia IBIMET
CNR Bologna
Italy
M. Minacapilli and G. Rallo
Dipartimento SAGA
Università degli Studi di Palermo
Italy

G. D'Urso
Dipartimento IAAT
Università degli Studi di Napoli “Federico II"
Italy

Keywords: olive, grapevine, orange, tree capacitance, hysteresis

\begin{abstract}
Evapotranspiration estimation by micrometeorological techniques through the assessment of mass and energy exchanges in the soil-plant-atmosphere continuum (SPAC) is a very active research area, involving both well-known and novel measurement techniques. A crucial aspect in validating experimental results is the integration of independent measurements of mass and energy exchanges in the SPAC. To this aim, the development and validation of an integrated approach in major tree crop species, involving different independent techniques, are presented. Eddy covariance estimates of ET fluxes were compared to up-scaled sap flow measurements in olive, orange and grapevine, three important Mediterranean tree crop species with contrasting ecophysiological characteristics and responses to water deficits. These differences can affect directly the degree of coupling of the tree to the environment and, consequently, the degree of correspondence between instantaneous transpirational flux at tree level and the micrometeorological measurement of ET at orchard level. Data were analyzed to verify to what extent, in the three species, transpirational flow at orchard level is regulated by tree conductance, capacitance effects related to tree size or by environmental demand. Hourly observations were helpful in detecting physiological processes of the three species only when data were analyzed taking into consideration their diurnal changes.
\end{abstract}

\section{INTRODUCTION}

Estimation of water vapour exchange at orchard level, due to the technical advancements in field instrumentation and data availability, allows fairly accurate evaluations of water consumption by fruit crops. Current micrometeorological measurement techniques, such as "eddy covariance", "scintillometry" or "surface renewal", generally aim to observe fluxes over a footprint that includes a large number of trees. However, in these techniques, the estimated water vapour flux represents an aggregate value (Williams et al., 2004), which includes the sum of all water losses from each tree within the footprint area (Oishi et al., 2008). Furthermore, depending on the employed technique, the source area can represent only a limited part of the entire orchard. In relation to the differences in vigour existing among trees, the amount of transpiration flux from each tree can vary not only as a function of leaf area (Williams and Ayars, 2005), but also because, at the same transpiration rate, trees can experience different levels of water deficit (Sperry et al., 2003) depending on their hydraulic 
architecture. As a consequence, the development of up-scaling techniques of physiological processes to the landscape level, able to cope with the complexity and variability of processes involved in tree transpiration, is still considered important (DePury and Farquhar, 1997; Chen et al., 2008), specifically when comparing micrometeorological to tree-level observations. The same issues arise when observing the transpiration process at different time-scales, where physiological control prevails at the higher time resolutions (Porte-Agel et al., 2000; Phillips and Oren, 1998).

Under this respect, eddy covariance (EC) versus sapflow (SF) observations can be considered the preferred method of investigation to assess the relative importance of the different processes involved in orchard transpiration. Even if tree-level calibration techniques at hourly time scale are very well established (Fernandez et al., 2001), comparisons between EC and SF fluxes have to be carried out at a daily scale, due to the time lag caused by tree capacitance (Pernice et al., 2009) and by the strong stomatal control of transpiration exerted in tree crops like olive (Sofo et al., 2008). In fact, tree capacitance affects hourly values of transpiration, generating time lag effects between the different scales of measurement with strongly non-linear relationships. The analysis of the latter phenomena is the aim of this study in order to link the diurnal dynamics of EC and SF fluxes to the specific degree of decoupling of each tree species to the environmental demand. Particularly we focused on orange (Citrus sinensis), olive (Oleaeuropaea) and grapevine (Vitis vinifera), representing the three most important Mediterranean woody crops species, characterized by contrasting ecophysiological characteristics, size of the individual plant and stomatal responses to water deficits.

\section{MATERIAL AND METHODS}

Experiments were carried out in Sicily (Italy) in three farms located near Castelvetrano (olive, 'Nocellara del Belice'), Campobello di Mazara (grapevine, 'Chardonnay') and Catania (orange, 'Tarocco'). The Sicilian climate is typical Mediterranean, with moderate rainfall distributed during autumn and winter and warm, dry summers. Investigations were carried out during 2010 irrigation season by means of sap flow (SF) and eddy covariance (EC) installations. Table 1 summarizes the main characteristics of the study sites and the instrumentations used during the observation period.

\section{Eddy Covariance}

The turbulent fluxes in the low atmosphere can be observed on the basis of the eddy covariance technique by means of high frequency measurements of threedimensional wind velocity, temperature fluctuations, and scalar quantities (e.g., water vapour, $\mathrm{CO}_{2}$ ). For the three sites, wind velocity and temperature fluctuations were measured by a three dimensional sonic anemometer (CSAT3-3D, Campbell Sci., USA). In site 1 (orange) and 2 (olive), water vapour concentration were measured by an openpath, infrared absorption gas analyser (IRGA) (LI7500, LiCor Inc., USA), whereas in the site 3 (grapevine) a Kripton thermo-hygrometer was used. These instruments were installed above the canopy (at about twice the average tree height from ground). For the three sites, on top of the same height, also a net radiometer (NR Lite, Campbell Sci., USA) was placed to measure the net available energy at the surface; moreover, heat fluxes in the soil were measured through a set of soil heat flux plates (HFP01, Campbell Sci., USA) placed at a depth of $5 \mathrm{~cm}$. Eddy covariance post-processing was done to obtain 30-minute average fluxes.

\section{Sap Flow}

Measurements of water consumption at tree level were done by using HPV (Heat Pulse Velocity - Swanson and Whitfield, 1981) technique in the site 1 and TDP (Thermal Dissipation Probe - Granier, 1987) technique in the sites 2 and 3. For HPV measurements, two 4cm sap flow probes with 4 thermocouples embedded (Tranzflo NZ Ltd., Palmerston North, NZ) were inserted in the trunks of three trees. The probes were positioned at north 
and south sides of the trunk at $50 \mathrm{~cm}$ from the ground and wired to a data-logger (CR1000, Campbell Sci., USA) for heat-pulse control and measurement; sampling interval was $30 \mathrm{~min}$. Data of the two probes were processed according to Green et al. (2003) to integrate sap flow velocity over sapwood area and calculate transpiration. To this purpose, fraction of water in the sapwood was determined both on sample trees, during the experiment, and directly on the trees where sap flow probes were installed, at the end of the observation period. Wound-effect correction (Green et al., 2003) was done on a per-tree basis. Fluxes up-scaling was done on the basis of the ratio between orchard leaf area index (LAI) and tree leaf area.

\section{RESULTS AND DISCUSSION}

Scatterplots of SF vs. EC hourly values showed the same general dependence pattern for all three species, characterized by a saturation-type response, with a good degree of linearity at low EC values and a lack of increases of SF at high EC flux values (Fig. 1).

Separating data on the basis of the day time, SF vs. EC hourly dependence changed according to the species. In orange trees (Fig. 1a), a fairly good linearity was observed both in morning and afternoon values, whereas midday values showed a weak relationship, with a small slope value, denoting lower xylem flux (SF values) in comparison to canopy transpiration as estimated by EC. The lack of relationship between EC and SF for midday values was observed also for the other species. In the grapevine (Fig. 1c), a linear SF vs. EC relationship was observed only in the morning, while afternoon SF fluxes were almost similar to midday values and about half of the EC ones. The opposite behavior was observed in the olive (Fig. 1b), where a linear relationship was observed only in the afternoon, and SF fluxes about half of the EC values were measured both in morning and midday hours.

Analysis of daily variation of average EC and SF fluxes (Fig. 2) shows that SF divergence from EC begins at about 10:00 local time for all the three species. Midday SF fluxes were almost steady for large part of the period while EC ones followed the daily trend of atmospheric evapotranspiration demand, with the exception for grapevine (Fig. 2c), which showed a mid-day reduction both in canopy transpiration (EC) and sap flow. This reduction can be related to the deficit irrigation regime adopted for grapevine.

Midday differences between SF and EC in orange (Fig. 2a) and olive (Fig. 2b) denote a depletion of plant water content in relation to the unbalance between tree crown water loss by transpiration, as estimated by EC, and water transport from the belowground part of the tree as estimated by SF. This unbalance, in both olive and orange, is recovered in the afternoon and nocturnal hours, with SF higher than EC fluxes (Fig. 2), so that daily cumulative SF and EC fluxes (Fig. 3) reached about the same values. In olive the unbalance between SF and EC fluxes was larger than in orange, both during midday and afternoon hours, probably in relation to a higher tree capacitance.

Large part of the differences in water use dynamics observed in this study could be interpreted by tree capacitance. The unbalance between canopy transpiration and tree water uptake observed, in olive (Fig. 4b) more than in orange (Fig. 4a), is revealed by the large hysteresis occurred, with higher afternoon SF values. It is interesting to note that the hysteresis loop of olive and orange appears specularly reflected, with a larger hysteresis in the morning-midday hours in orange and, in contrast, a larger hysteresis during afternoon-nighttime hours in olive. This difference may be related to the contrasting water use strategies of the two species. Differently, in grapevine the hysteresis loop is less marked and it mainly occurs only in midday hours (Fig. 4c), probably in relation to the water stress condition of the vineyard.

\section{CONCLUSIONS}

Simultaneous use of EC and SF measurements provides an interesting experimental approach to obtain an insight of biophysical behaviour of tree crops. The different mechanisms regulating water use of the three species, which largely affected the 
flux comparison at hourly scale, could be detected only if correctly analyzed. Hourly observations were helpful in detecting physiological processes of the three species only when data were analyzed taking into consideration their diurnal changes, i.e., clustering data by the time of day, representing their changes and accumulation during the day and by analyzing the presence of hysteresis loops. These effects generally cannot be observed at daily scale, normally used when comparing SF to EC.

From an ecophysiological point of view, diurnal changes in tree or soil water flux resistances might play an important role in explaining the differences between species, particularly in orange and grapevine. By contrast, capacitance in olive seems to play a pivot role in the diurnal regulation of water consumption of this species causing a decoupling of SF measured at trunk level vs. canopy transpiration, which is well pointed out by the strong hysteresis shown by this species.

\section{ACKNOWLEDGEMENTS}

This work has been carried out in the context of the Project of Relevant National Interest (P.R.I.N.) 2008 "Assessment of mass and energy fluxes for the irrigation management of Mediterranean tree crops" under grant no. 2008CR84NF by Italian Ministry of Research and University (M.I.U.R.).

The authors wish to thank the "Azienda Agricola Tenuta Rocchetta di Angela Consiglio", Azienda Tribulato (Lentini, SR), and Azienda "Tenuta Gorghi Tondi" for their hospitality. Authors are also grateful to the Agrometeorological Service (SIAS) of the Sicilian Region for its enthusiastic cooperation and support.

\section{Literature Cited}

Chen, C.P., Zhu, X.G. and Long, S.P. 2008. The effect of leaf-level spatial variability in photosynthetic capacity on biochemical parameter estimates using the Farquhar Model: a theoretical analysis. Plant Physiol. 148:1139-1147.

DePury, D.G.G. and Farquhar, G.D. 1997. Simple scaling of photosynthesis from leaves to canopies without the errors of bigleaf models. Plant Cell Environ. 20:537-557.

Fernandez, J.E., Palomo, M.J., Diaz-Espejo, A., Clothier, B.E., Green, S.R., Giron, I.F. and Moreno, F. 2001. Heat-pulse measurements of sap flow in olives for an automating irrigation: tests, root flow and diagnostics of water stress. Agr. Water Manage. 51:99-123.

Granier A. 1987. Evaluation of transpiration in a Douglas-fir stand by means of sap flow measurements. Tree Physiol. 3:309-320.

Green, S., Clothier, B. and Jardine, B. 2003. Theory and practical application of heat pulse to measure sap flow. Agron. J. 95:1371-1379.

Oishi, A.C., Oren, R. and Stoy, P.C. 2008. Estimating components of forest evapotranspiration: A footprint approach for scaling sap flux measurements. Agr. Forest Meteorol. 148:1719-1732.

Phillips, N. and Oren, R. 1998. A comparison of daily representations of canopy conductance based on two conditional time averaging methods and the dependence of daily conductance on environmental factors. Ann. Sci. For. 55:217-235.

Pernice, F., Motisi, A., Rossi, F., Georgiadis, T., Nardino, M., Fontana, G., Dimino, G. and Drago, A. 2009. Micrometeorological and sap flow measurement of water vapour exchanges in olive: scaling up from canopy to orchard. Acta Hort. 846:159-166.

Porte-Agel, F., Parlange, M.B., Cahill, A.T. and Gruber, A. 2000. Mixture of time scales in evaporation: desorption and self-similarity of energy fluxes. Agron. J. 92:832-836.

Sofo, A., Manfreda, S., Fiorentino, M., Dichio, B. and Xiloyannis, C. 2008. The olive tree: a paradigm for drought tolerance in Mediterranean climates. Hydrol. Earth Syst. Sci. 12:293-301.

Sperry, J.S., Stiller, V. and Hacke, U.G. 2003. Xylem hydraulics and the soil-plantatmosphere continuum: opportunities and unresolved issues. Agron. J. 95:1362-1370.

Swanson, R.H. and Whitfield, D.W. 1981. A numerical analysis of heat pulse velocity theory and practice. J. Exp. Bot. 32:221-239. 
Williams, D.G., Cable, W., Hultine, K., Hoedjes, J.C.B., Yepez, E.A., Simonneaux, V., Er-Raki, S., Boulet, G., de Bruin, H.A.R., Chehbouni, A., Hartogensis, O.K. and Timouk, F. 2004. Evapotranspiration components determined by stable isotope, sap flow and eddy covariance techniques. Agr. Forest Meteorol. 125:241-258.

Williams, L.E. and Ayars, J.E. 2005. Grapevine water use and the crop coefficient are linear functions of the shaded area measured beneath the canopy. Agr. Forest Meteorol. 132: 201-211.

\section{Tables}

Table 1. Orchard features, observation period and instrumentation setup in each site.

\begin{tabular}{|c|c|c|c|c|}
\hline Site & $\begin{array}{c}\text { Orchard } \\
\text { characteristics }\end{array}$ & $\begin{array}{l}\text { Observ. } \\
\text { period }\end{array}$ & $\begin{array}{c}\text { Eddy covariance } \\
\text { setup }\end{array}$ & $\begin{array}{l}\text { Sap flow } \\
\text { setup }\end{array}$ \\
\hline 1. 01 & $\begin{array}{l}\text { LAI 3.0 } \\
\text { full irrigation } \\
\text { Spacing: } 4.0 \times \\
5.5 \mathrm{~m} \\
\text { TCSA*: } 215 \\
\mathrm{~cm}^{2}\end{array}$ & $\begin{array}{l}\text { July - } \\
\text { August }\end{array}$ & $\begin{array}{l}\text { High frequency }(10 \mathrm{~Hz}) \text { : } \\
\text { 3-D sonic anemometer } \\
\text { Infrared gas analyzer } \\
\text { Low frequency (30-min): } \\
\text { 4-component net radiometer } \\
\text { Three heat flux plates }\end{array}$ & $\begin{array}{l}\text { Three trees } \\
\text { two HPV } \\
\text { probes per } \\
\text { tree, } 50 \mathrm{~mm} \\
\text { length } \\
\text { (sensing } \\
\text { parts: } 5,15 \text {, } \\
25,45 \mathrm{~mm} \text { ) }\end{array}$ \\
\hline Fisa & $\begin{array}{l}\text { LAI } 1.5 \\
\text { deficit irrigated } \\
\text { Spacing: } 5 \times 8 \\
\text { m } \\
\text { TCSA: } 370 \mathrm{~cm}^{2}\end{array}$ & $\begin{array}{l}\text { July - } \\
\text { August }\end{array}$ & $\begin{array}{l}\text { High frequency }(20 \mathrm{~Hz}) \text { : } \\
\text { 3-D sonic anemometer } \\
\text { Infrared gas analyzer } \\
\text { Low frequency ( } 30 \text {-min): } \\
\text { 4-component net radiometer } \\
\text { Three heat flux plates }\end{array}$ & $\begin{array}{l}\text { Three trees } \\
\text { two Thermal } \\
\text { Dissipation } \\
\text { Probes (TDP; } \\
\text { Granier, } \\
\text { 1987) per } \\
\text { tree }\end{array}$ \\
\hline & $\begin{array}{l}\text { LAI } 1.2 \\
\text { deficit irrigated, } \\
\text { no irrigation in } \\
\text { the observation } \\
\text { period } \\
\text { Spacing: } 2 \times 1 \\
\text { m } \\
\text { TCSA: } 100 \mathrm{~cm}^{2}\end{array}$ & July & $\begin{array}{l}\text { High frequency }(20 \mathrm{~Hz}) \text { : } \\
\text { 3-D sonic anemometer } \\
\text { Kripton thermo-hygrometer } \\
\text { Low frequency ( } 30 \text {-min): } \\
\text { 4-component net radiometer } \\
\text { Three heat flux plates }\end{array}$ & $\begin{array}{l}\text { Three vines } \\
\text { two TDP per } \\
\text { vine }\end{array}$ \\
\hline
\end{tabular}

*: TCSA: Trunk Cross-Sectional Area 


\section{Figures}
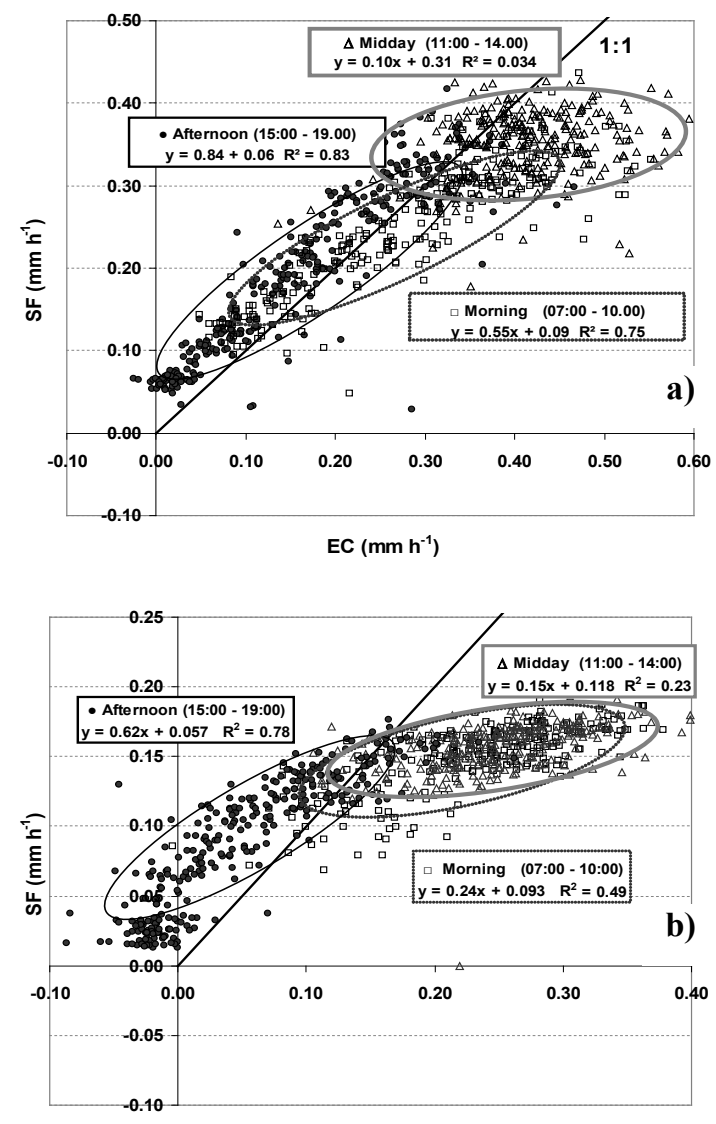

$E C\left(\mathrm{~mm} \mathrm{~h}^{-1}\right)$

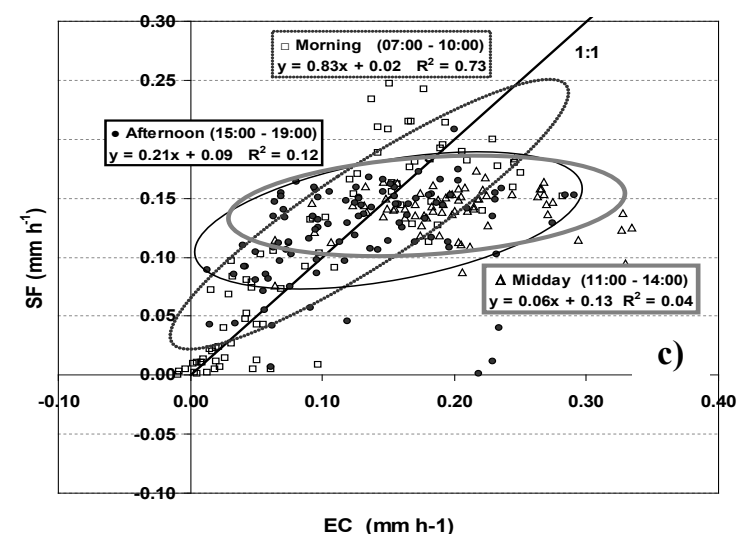

Fig. 1. Scatterplots of hourly values of daytime upscaled trunk SF vs. EC estimates of ET in orange (a), olive (b), and grapevine (c). Observation period was JulyAugust in orange and olive and July in grapevine. Bivariate confidence ellipses were calculated separately for morning, midday and afternoon hours.
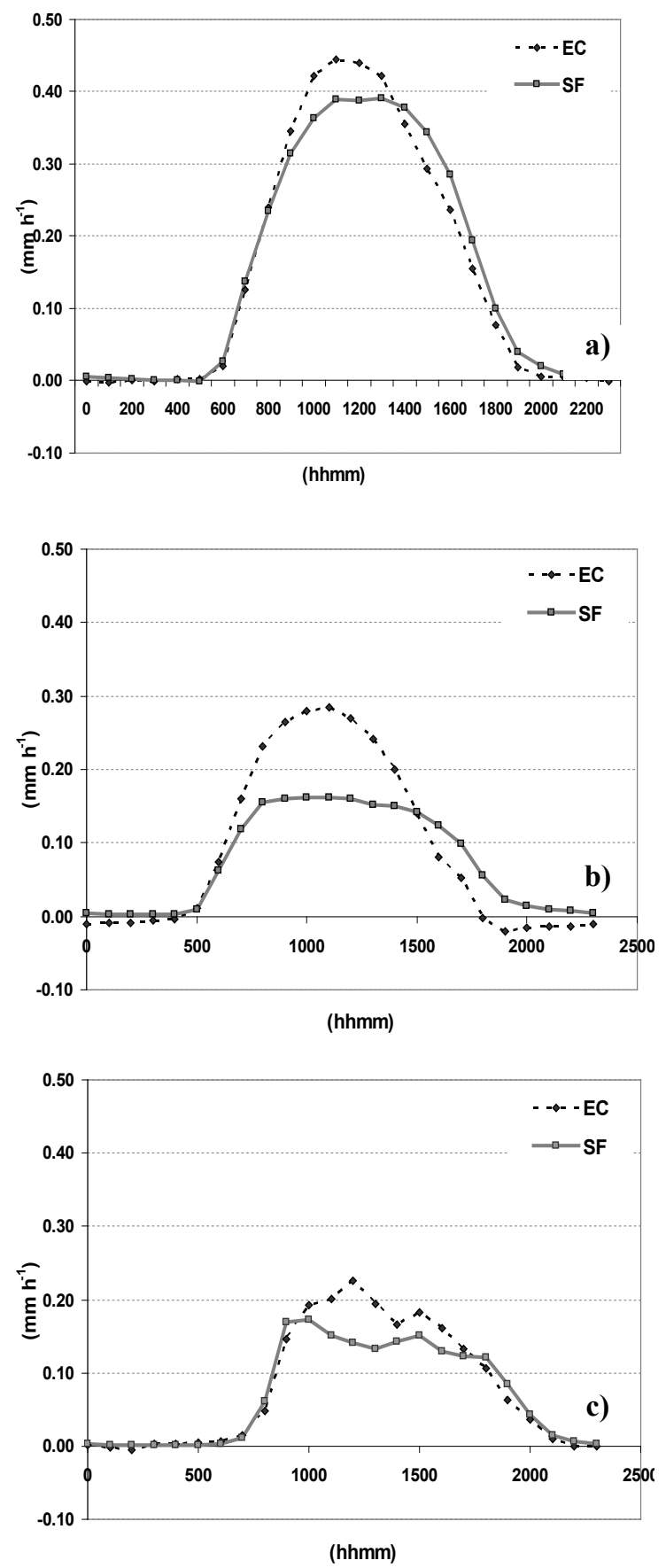

Fig. 2. Diurnal changes of upscaled SF in orange (a), olive (b) and grapevine (c). Each datapoint represents the average of all the values in the observation period (July-August in orange and olive, July in grapevine). 

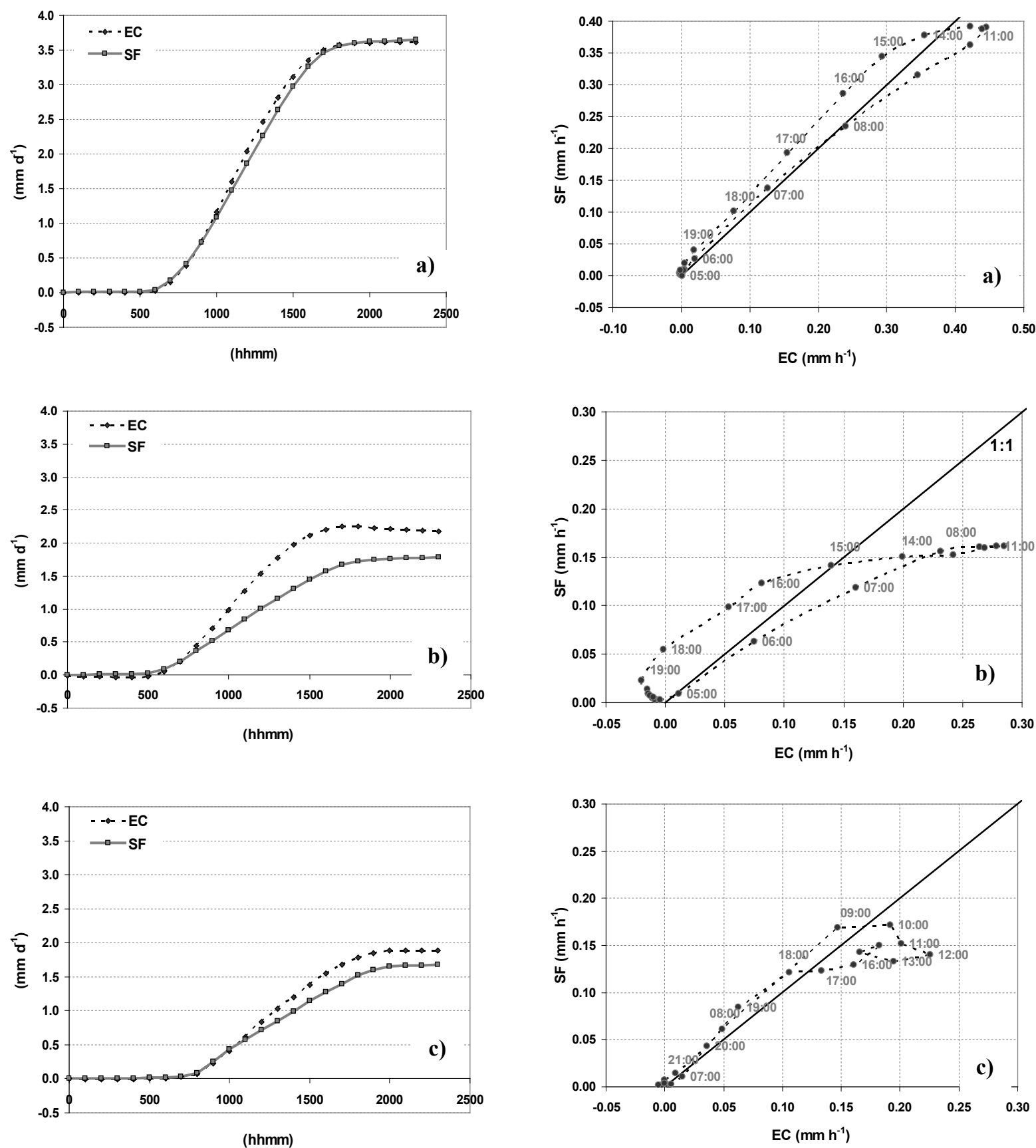

Fig. 3. Diurnal accumulation of upscaled trunk SF and EC estimates of ET in orange (a), olive (b), and grapevine (c). Each datapoint represents the average of all the values in the observation period (July-August in orange and olive, July in grapevine).

Fig. 4. Average diurnal hysteresis loops between upscaled trunk SF and EC estimates of ET in orange (a), olive (b), and grapevine (c) Each datapoint represents the average of all the values in the observation period (July-August in orange and olive, July in grapevine). 